\title{
Corticosteroid-resistant Bronchial Asthma Is Associated with Increased c-fos Expression in Monocytes and T Lymphocytes
}

\author{
Stephen J. Lane, ${ }^{\star}$ Ian M. Adcock, ${ }^{\ddagger}$ David Richards, ${ }^{\star}$ Catherine Hawrylowicz, ${ }^{\star}$ Peter J. Barnes, ${ }^{\ddagger}$ and Tak H. Lee \\ *Departments of Respiratory Medicine and Allergy, Guy’s Hospital, London SE1 9RT, United Kingdom; and ${ }^{\ddagger}$ Department of Thoracic \\ Medicine, National Heart and Lung Institute, Dovehouse Street, London SW3 6LY, United Kingdom
}

\begin{abstract}
Unstimulated peripheral blood mononuclear cells (PBMCs) from corticosteroid-resistant (CR) but not corticosteroidsensitive (CS) asthmatics demonstrate increased activating peptide-1 (AP-1)- and decreased glucocorticoid receptor (GR)-DNA binding. We test whether these abnormalities are associated with excessive generation of c-fos, the inducible component of AP-1. The c-fos transcription rate, mRNA and protein levels, and GR-DNA binding were quantitated in PBMCs, T cells, and monocytes from CS, $\mathrm{CR}$, and nonasthmatic subjects. There was a 1.7-, 4.2-, and 2.3-fold greater increase in the baseline c-fos transcription rate, mRNA expression, and protein levels, respectively, in PBMCs derived from CR compared with CS patients. At optimal stimulation with PMA, there was a 5.7-, 3.4-, and 2-fold greater increase in the c-fos transcription rate, mRNA accumulation, and protein levels, respectively, in CR compared with CS PBMCs. These abnormalities were detected in both the $T$ cell and monocyte subpopulations. PMA stimulation converted PBMCs from a CS to a CR phenotype and was associated with direct interaction between c-Fos and the GR. Pretreatment of PBMCs from CR patients with c-fos antisense oligonucleotides enhanced GR-DNA binding activity in CR PBMCs stimulated with dexamethasone. We suggest that increased c-fos synthesis provides a major mechanism for the increased AP-1- and decreased GRDNA binding seen in CR asthma. (J. Clin. Invest. 1998. 102: 2156-2164.) Key words: asthma • glucocorticoid • c-fos • AP-1 • mononuclear cells
\end{abstract}

\section{Introduction}

Corticosteroids are very effective treatment for bronchial asthma. They improve airflow obstruction in both adults and children and decrease the accelerated decline in lung function associated with asthma (1). Corticosteroids suppress the cellular infiltration of the asthmatic airways and decrease associated production of proinflammatory cytokines both in vitro and in vivo via different mechanisms (2). There are, however, a small number of asthmatic subjects who do not benefit from

Address correspondence to Prof. T.H. Lee, Department of Respiratory Medicine and Allergy, 5th Floor, Thomas Guy House, Guy's Hospital, London SE1 9RT, U.K. Phone: 44-0171-955-4571; FAX: 44-0171-403-8640; E-mail: t.lee@umds.ac.uk

Received for publication 30 December 1997 and accepted in revised form 19 October 1998.

J. Clin. Invest.

(C) The American Society for Clinical Investigation, Inc. 0021-9738/98/12/2156/09 \$2.00

Volume 102, Number 12, December 1998, 2156-2164

http://www.jci.org corticosteroids (3). The molecular mechanism of this resistance is unclear. Although this phenomenon is relatively uncommon, it poses a difficult therapeutic problem because few alternative therapies are available. Corticosteroid resistance, although seen in most inflammatory conditions, has been most extensively studied in bronchial asthma where failure to respond is more easily documented (4).

Corticosteroid-resistant $(\mathrm{CR})^{1}$ asthma has been defined as a failure of the forced expired volume in $1 \mathrm{~s}\left(\mathrm{FEV}_{1}\right)$ to improve from a baseline value of $\leq 75 \%$ predicted by $\geq 15 \%$ after $14 \mathrm{~d}$ of treatment with $40 \mathrm{mg}$ of prednisolone orally, despite demonstrating $>15 \%$ reversibility to an inhaled $\beta_{2}$-agonist (5). CR asthma is associated with impaired in vitro and in vivo responsiveness of peripheral blood mononuclear cells (PBMCs) to the suppressive effects of corticosteroids (5). Recent studies using in situ hybridization techniques have shown that there is reduced suppression of IL-4 and IL-5 mRNA in bronchoalveolar lavage cells obtained from CR patients after $1 \mathrm{wk}$ of treatment with prednisolone, when compared with those of corticosteroid-sensitive (CS) asthmatic subjects (6).

At a molecular level, resistance to the antiinflammatory effects of corticosteroids in asthma may be a heterogeneous phenomenon. Sher et al. have described two patterns of ligandbinding abnormalities in a group of CR asthmatics termed type 1 and 2 (7). The more common type 1 defect was associated with reduced binding affinity $\left(K_{\mathrm{d}}\right)$ of the glucocorticoid receptor (GR), normal receptor numbers, localization to $\mathrm{T}$ cells, reversibility with serum deprivation, and was IL-2 and IL-4 dependent. The less common type 2 defect was associated with reduced GR receptor density with a normal $K_{\mathrm{d}}$, was irreversible, and was seen in the total mononuclear cell population. We have demonstrated normal $K_{\mathrm{d}}$ and receptor density of the GR in the monocyte subpopulation, while the ligandbinding affinity of the GR in $\mathrm{T}$ cells of patients with $\mathrm{CR}$ asthma was found to be reduced fourfold $(8,9)$. We have also recently demonstrated that PBMCs from $\mathrm{CR}$ asthmatics have fewer GRs available for DNA binding than CS subjects despite normal structure of the GR $(10,11)$. In addition, there is an increase in DNA binding of the transcription factor activating peptide-1 (AP-1) in mononuclear cells in CR subjects, suggesting that the increase in AP-1 may sequester available GRs, thereby overwhelming the latter's antiinflammatory action (12). A possible mechanism underlying the increase in AP-1DNA binding is overproduction of one or more of the components of AP-1.

AP-1 is a transcription factor complex that is formed by dimerization of members of the Fos (c-Fos, Fra1, and Fra2) and Jun (c-Jun, JunB, and JunD) protooncogene families and

1. Abbreviations used in this paper: AP-1, activating peptide-1; CR, corticosteroid-resistant; CS, corticosteroid-sensitive; EMSA, electrophoretic mobility shift assay; GR, glucocorticoid receptor; PBMC, peripheral blood mononuclear cell; ROU, relative optical unit. 
is defined by binding to the tetradecanoyl phorbol 13-acetate (TPA)-responsive element (TRE) on DNA chromatography (13). In the resting cell, AP-1 is composed of dimers of the c-jun family, i.e., Jun:Jun homodimers or c-Jun:JunB interfamily heterodimers because there is little available c-Fos. These dimers have weak DNA binding and transactivating activities, partly due to $\mathrm{COOH}$-terminal phosphorylation. When the cell is activated, c-jun is dephosphorylated at its $\mathrm{COOH}$-terminal end, phosphorylated at its $\mathrm{NH}_{2}$-terminal end, and increases in quantity. In addition, there is rapid induction of c-Fos, which forms transient but highly thermostable heterodimeric complexes with newly generated c-Jun, which displaces basal AP-1 activity. These heterodimers demonstrate increased DNA binding and transactivating ability. The most abundant AP-1 heterodimer is c-Fos:c-Jun, and c-Fos expression is thereby the inducible marker of the most transcriptionally active AP-1 complex. AP-1 activates the IL-4, IL-5, and GM-CSF genes, which are important in asthma pathogenesis $(14,15)$. In addition, IL-5 and GM-CSF activate c-fos transcription and may provide one mechanism perpetuating the asthmatic inflammatory process $(16,17)$.

We hypothesize that the increased DNA binding of AP-1 and the decrease in DNA binding of the GR seen in CR asthmatic mononuclear cells results, at least in part, from increased generation of c-fos, the inducible component of AP-1. Excess AP-1 will inhibit the antiinflammatory effects of a limited number of available GRs in any given cell, thereby perpetuating AP-1-mediated inflammation, which may result in CR inflammation (18).

\section{Methods}

Selection of patients. $12 \mathrm{CS}, 12 \mathrm{CR}$, and 6 nonasthmatic subjects matched in terms of age, gender, atopic status, cigarette smoking history, and baseline predicted $\mathrm{FEV}_{1}$ were studied (Table I). The asthmatic patients were taken from a panel of patients with previously well-documented defects in GR- and AP-1-DNA binding $(10,12)$. $\mathrm{FEV}_{1}$ was measured when the patients were stable, albeit with reduced lung function. Both of the asthmatic groups demonstrated a $<30 \%$ improvement in $\mathrm{FEV}_{1}$ either spontaneously or after $400 \mu \mathrm{g}$ of inhaled albuterol via a metered dose inhaler. The CS group demonstrated an improvement of $33 \pm 2 \%$ (mean \pm SEM) in $\mathrm{FEV}_{1}$ after a 2 -wk course of $40 \mathrm{mg}$ of prednisolone. The CR group, however, demonstrated an improvement of only $3 \pm 0.8 \%$ (mean \pm SEM) after a similar course of treatment $(P<0.001)$. There was no difference between the two groups in the use of medication. All patients were receiving inhaled albuterol on an as-required basis. The mean dose per day for albuterol was $2,600 \pm 400 \mu \mathrm{g}$ (mean \pm SEM) and $2,800 \pm 600 \mu \mathrm{g}$ (mean \pm SEM) in the CS and CR groups, respectively, and none of the patients was receiving inhaled corticosteroids at the time of the study. There was no difference in atopic status among the groups, and none of the subjects had taken oral corticosteroids for at least 3 mo prior to the study. Ethical approval was granted by Guy's Hospital Committee on Ethical Practice, and written informed consent was obtained from each patient.

Cell separation and culture. PBMCs were separated by centrifugation over Lymphoprep (Nycomed, Birmingham, UK) as previously described and suspended at a density of $10^{7} / \mathrm{ml}$ (11). $1 \mathrm{ml}$ of the PBMC suspension was then incubated at $37^{\circ} \mathrm{C}$ with $0-10 \mathrm{ng} / \mathrm{ml}$ PMA at different time points from $0-50 \mathrm{~min}$, at which time the reaction was stopped and total cellular RNA extracted in $4 \mathrm{M}$ guanidinium as previously described (11). Monocytes were separated by density gradient centrifugation and resuspended at $5 \times 10^{5} / \mathrm{ml}$ to a purity of $91 \pm 2 \%$. CD4 T lymphocytes were separated using Dynabeads (Dynal, Wirral,
Table I. Clinical Characteristics of Asthmatic Patients

\begin{tabular}{lcc}
\hline & CS & CR \\
\hline Number & 12 & 12 \\
Age (yr) & $49 \pm 4$ & $51 \pm 4$ \\
Gender & $7 \mathrm{M}$ & $8 \mathrm{M}$ \\
\% predicted FEV & $64 \pm 5$ & $61 \pm 8$ \\
\% albuterol response* & $32 \pm 2$ & $34 \pm 3$ \\
\% prednisolone response & $33 \pm 2$ & $3 \pm 0.8^{\ddagger}$ \\
Smokers & 1 & 0 \\
Atopic & $4 / 12$ & $5 / 12$ \\
& & \\
\hline
\end{tabular}

*Albuterol response is the percent increase in $\mathrm{FEV}_{1}$ after administration of $400 \mu \mathrm{g}$ albuterol via a metered dose inhaler. ${ }^{\ddagger}$ Prednisolone response is the percent increase in $\mathrm{FEV}_{1}$ after a 2-wk dose of $40 \mathrm{mg} /$ day orally. ${ }^{*} P<0.001$. Values are mean \pm SEM. $M=$ males.

U.K.), class 2, and natural killer cells depleted using anti-HLA DR and anti-CD16 (Seralab, Crawley Down, U.K.), respectively, and resuspended at $1 \times 10^{6} / \mathrm{ml}$ to a purity of $97 \pm 3 \%$.

Quantitative reverse transcription (RT)-PCR of c-fos $m R N A$. Total RNA was reverse transcribed as previously described (11). PCR was performed on a cDNA aliquot to subsaturation by primers encoding a $340 \mathrm{bp}$ sequence of the 1 st and 2 nd exons of the human c-fos gene (20-25 cycles) and a 159 bp sequence of the human $\beta$-actin gene (18 cycles). The c-fos primer sequences were designed with MacVector Software (Oxford Molecular, Oxford, U.K.) and derived from exon 1 and exon 2 of genomic c-fos, i.e., 5', GGC TTC AAC GCA GAC TAC GAG G 301-322 exon 1 to 3' CTC CTG TCA TGG TCT TCA CAA CG 1393-1371 exon 2 . The $\beta$-actin cDNA sequence was 5' CAC CAC ACC TTC TAC AAT GAG CTG C 1483-1507 to 3' ACA GCC TGG ATA GCA ACG TAC ATG G 2057-2081 (HPLC purified; R\&D Systems Europe Ltd., Abingdon, Oxon, U.K.). 18-25 cycles of PCR amplification were carried out under the following conditions. The first four cycles were at $90 \mathrm{~s}$ denaturation at $95^{\circ} \mathrm{C}, 10$ min at $60^{\circ} \mathrm{C}$ annealing, and $120 \mathrm{~s}$ primer extension at $72^{\circ} \mathrm{C}$. The next $14-21$ cycles were at $90 \mathrm{~s}$ denaturation at $95^{\circ} \mathrm{C}, 120 \mathrm{~s}$ at $60^{\circ} \mathrm{C}$ annealing, and $120 \mathrm{~s}$ primer extension at $72^{\circ} \mathrm{C}$. The initial denaturation period was $90 \mathrm{~s}$, and the final extension time was $10 \mathrm{~min}$. The PCR products were resolved on a $2.8 \%$ agarose gel and quantitated by laser densitometry. The amount of c-fos and $\beta$-actin mRNA transcripts per microgram of original RNA sample was calculated using an established method (19). Data were plotted as c-fos mRNA transcripts as a percentage of corresponding $\beta$-actin transcripts.

Transcriptional run-on assays. For transcriptional analysis, PBMC nuclei were isolated from two CS and two CR subjects after 20 min of stimulation in the presence or in the absence of $10 \mathrm{ng} / \mathrm{ml}$ PMA in a cell lysis buffer containing $0.5 \%(\mathrm{vol} / \mathrm{vol}) \mathrm{NP}-40$, and transcription continued in the presence of $100 \mu \mathrm{Ci}$ of $\alpha{ }^{3}{ }^{32} \mathrm{P}$-labeled UTP according to an established method (20). Hybridization to an immobilized c-fos cDNA template derived from a nonasthmatic subject by RT-PCR was performed at $65^{\circ} \mathrm{C}$ for $36 \mathrm{~h}$, after which the membranes were washed twice in $1 \times \mathrm{SSC} / 0.2 \% \mathrm{SDS} / 10 \mathrm{mM}$ sodium phosphate $/ 1 \mathrm{mM}$ EDTA at $22^{\circ} \mathrm{C}$ for $5 \mathrm{~min}$, and twice in $0.2 \times \mathrm{SSC} / 0.2 \% \mathrm{SDS} / 10 \mathrm{mM}$ sodium phosphate $/ 1 \mathrm{mM}$ EDTA at $65^{\circ} \mathrm{C}$ for $15 \mathrm{~min}$, after which autoradiographic densitometric analysis was performed and data were expressed in relative optical units (ROUs).

Western analysis of c-Fos protein. PBMCs were incubated with $10 \mathrm{ng} / \mathrm{ml}$ PMA for various times up to $10 \mathrm{~h}$. At each time point, cells $\left(2 \times 10^{6}\right)$ were washed and soluble cell proteins extracted by freezethawing in extraction buffer. $50 \mathrm{mg}$ of protein from each sample was size fractionated on a $10 \%$ SDS-PAGE gel and transblotted onto nitrocellulose-enhanced chemiluminescence (ECL) membranes (Am- 
ersham Int., Amersham, U.K.). Membranes were blocked overnight with $2 \%$ casein in PBS-Tween before incubation with 1:500 sheep anti-human c-Fos antibody (Serotec, Oxford, U.K.) at $18^{\circ} \mathrm{C}$ for $3 \mathrm{~h}$. After washing, bound antibody was detected using 1:5,000 donkey anti-sheep antibody linked to horseradish peroxidase, and bound complexes were detected by ECL (Amersham) and expressed in ROUs.

Electrophoretic mobility-shift assay (EMSA). PBMCs from three $\mathrm{CS}$ and three CR PBMCs were incubated for $6 \mathrm{~h}$ in the absence and in the presence of $10 \mathrm{ng} / \mathrm{ml}$ PMA. At the end of the incubation period, the medium was changed and the cells incubated with $1 \mu \mathrm{M}$ dexamethasone for a further $60 \mathrm{~min}$, at which time soluble nuclear proteins were extracted and GR-DNA binding performed by EMSAs as previously described (12).

Immunoprecipitation. $5 \times 10^{6} \mathrm{PBMCs}$ from two $\mathrm{CS}$ and two $\mathrm{CR}$ subjects were incubated for $30 \mathrm{~min}$ with $1 \mu \mathrm{M}$ dexamethasone and 10 ng/ml PMA. Cells were then pelleted and washed three times in HBSS. Cells were lysed in IP buffer $(50 \mathrm{mmol}$ Tris-HCl, $\mathrm{pH}$ 7.6, $1 \%$ Triton X-100, 0.1\% SDS, $150 \mathrm{mmol} \mathrm{NaCl}, 1 \mathrm{mmol}$ EDTA, $1 \mathrm{mmol}$ EGTA, $2 \mathrm{mmol} \mathrm{NaPPi}, 2 \mathrm{mmol} \mathrm{Na}_{3} \mathrm{VO}_{4}, 1 \mathrm{mmol} \mathrm{PMSF}$ ) and $50 \mathrm{mg}$ of protein and incubated for $18 \mathrm{~h}$ with constant shaking at $4^{\circ} \mathrm{C}$ with $5 \mu \mathrm{g}$ of anti-human c-Fos or anti-human GR polyclonal antibody. At the end of this time, $100 \mu \mathrm{g}$ of protein A-sepharose was added, and the cells were incubated for a further $30 \mathrm{~min}$ at $4^{\circ} \mathrm{C}$ with constant shaking. Protein A-immunoglobulin complexes were pelleted and washed three times in IP buffer. The pellet was resuspended in $30 \mu \mathrm{l}$ of $2 \times$ Laemmli buffer (0.1 M Tris-HCl, pH 6.8, 4\% SDS, 20\% glycerol, 1 mmol DTT, $0.001 \%$ bromophenol blue) and size fractionated by $7 \%$ SDS-PAGE. Size-fractionated proteins were transferred onto nitrocellulose membranes as described above and probed with anti-human GR or anti-human c-Fos polyclonal antibody, and immunoreactive protein bands were detected by ECL (Amersham). Preimmune serum was used as a control for nonspecific binding.

c-fos antisense assays. $5 \times 10^{6}$ PBMCs from four CS and four CR asthmatic subjects were preincubated with $10 \mathrm{mM}$ phosphothioate modified fos antisense (5'-TGCGTTGAAGCCCGAGAA-) or sense (5'-TTCTCGGGCTTCAACGCA-) oligonucleotides for $4 \mathrm{~h}$ at $37^{\circ} \mathrm{C}$ under optimal experimental conditions previously reported (21-24) and for which we have demonstrated attenuation of c-Fos expression in PBMCs under basal conditions and when cells were stimulated with $10 \mathrm{ng} / \mathrm{ml}$ PMA for $2 \mathrm{~h}$ at $37^{\circ} \mathrm{C}$ (data not shown). These nucleotide sequences were complementary to the first 18 bases following the AUG sequence of c-fos mRNA, and they then penetrated into the cells without any additional pretreatment. After preincubation, cells were washed and treated with dexamethasone $(1 \mathrm{mM})$ for $60 \mathrm{~min}$ at $37^{\circ} \mathrm{C}$. Cell proteins were employed to control for protein loading.

Statistical analysis. The data were normally distributed and means were expressed as the arithmetic mean \pm SEM. Inter- and intragroup means were compared using unpaired and paired Student's $t$ tests, respectively. Dose-response and kinetic curves were plotted for each patient and their underlying areas compared by nonpaired Student's $t$ tests. A $P$ value of $\leq 0.05$ was considered significant for each comparison.

\section{Results}

c-fos $m R N A$ accumulation in CR asthma. Comparison of c-fos/ $\beta$-actin mRNA levels from unstimulated PBMCs demonstrated a significant 4.2-fold elevation in the CR group as opposed to the CS group $(0.24 \pm 0.06 \% \mathrm{CR}$ vs. $0.056 \pm 0.02 \% \mathrm{CS}$; $P<0.01, n=12$ ) (Fig. 1, $a$ and $b$ ). There was no difference between nonasthmatic subjects $(0.12 \pm 0.05 \%, P=0.78 ; n=6)$ and the $\mathrm{CS}$ group in $\mathrm{c}-\mathrm{fos} / \beta$-actin expression in unstimulated PBMCs, whereas there was a significant difference as compared with the $\mathrm{CR}$ group $(P<0.05)$. c-fos $/ \beta$-actin expression was maximal when cells were stimulated with $10 \mathrm{ng} / \mathrm{ml}$ PMA for $20 \mathrm{~min}$ in all groups of subjects (Fig. 1, $a$ and $b$ ). At optimal conditions of stimulation, the increase in the $\mathrm{c}-f o s / \beta$-actin mRNA ratio was 3.4-fold greater in the CR group (2.01士 $0.1 \%, P<0.01)$ than in either the CS $(0.585 \pm 0.2 \%)$ or the nonasthmatic group $(0.49 \pm 0.15 \%)$.

The increase in c-fos expression was detected in both the unstimulated T cell $(0.33 \pm 0.12 \% \mathrm{CR}$ vs. $0.08 \pm 0.01 \% \mathrm{CS} ; P=$ $0.02, n=3)$ and monocyte $(0.38 \pm 0.06 \%$ CR vs. $0.09 \pm 0.02 \%$ $\mathrm{CS} ; P=0.025, n=3$ ) subpopulations, representing a 4.1-fold and 4.2-fold increase in the $\mathrm{CR}$, as opposed to the CS group, respectively (Fig. 2). Furthermore, when the cells were stimulated with $10 \mathrm{ng} / \mathrm{ml}$ PMA for $20 \mathrm{~min}$, there was a 4.1-fold $(2.07 \pm 0.14 \% \mathrm{CR}$ vs. $0.47 \pm 0.05 \% \mathrm{CS} ; P=0.01)$ and threefold $(1.95 \pm 0.06 \% \mathrm{CR}$ vs. $0.64 \pm 0.03 \% \mathrm{CS} ; P=0.01)$ greater increase in $\mathrm{c}-f o s / \beta$-actin mRNA ratio in the CR subpopulation, as compared with the CS, T cell, and monocyte subpopulations, respectively (Fig. 2).

c-fos transcription in CR asthma. In the first experiment, the transcription rate in unstimulated PBMCs was 7.4 ROUs and 14.7 ROUs in the CS and CR subjects, respectively. Following stimulation with $10 \mathrm{ng} / \mathrm{ml}$ PMA for $20 \mathrm{~min}$, the transcription rate increased to 11.8 ROUs and 85.3 ROUs in the $\mathrm{CS}$ and CR subjects, respectively. In the second experiment, the transcription rate in unstimulated PBMCs was 8.3 ROUs and 13.3 ROUs in the CS and CR subjects, respectively. Following stimulation with $10 \mathrm{ng} / \mathrm{ml}$ PMA for $20 \mathrm{~min}$, the transcription rate increased to 13.3 ROUs and 77 ROUs in the CS and CR subjects, respectively. Therefore, there was on average a 1.7-fold greater expression of c-fos in unstimulated PBMCs from CR as compared with CS subjects. PMA stimulated c-fos expression on average by 1.8 -fold and 5.8-fold in the CS and CR subjects, respectively. Therefore, there was an average 5.7fold greater increase in c-fos expression in CR as compared with CS subjects. These findings suggest that increased basal and stimulated transcription of c-fos underlie the increased mRNA accumulation described above but does not exclude contributions from a reduction in its degradation or increase in its transfer from the nucleus (Fig. 3).

c-Fos protein in CR asthma. Western blot analysis of the human c-Fos protein from $10 \mathrm{CS}$ and $10 \mathrm{CR}$ patients detected a single band of $55 \mathrm{kD}$ in all samples. Analysis of c-Fos expression in the absence of PMA stimulation revealed a 2.3-fold greater level of c-Fos in CR as opposed to CS subjects, which was maintained over a 10 -h incubation period in control media (0.22 \pm 0.03 ROUs for CS vs. $0.51 \pm 0.02$ ROUs for CR; $P<$ $0.02)$. Following incubation with $10 \mathrm{ng} / \mathrm{ml}$ PMA, the levels of c-Fos protein increased in both CR and CS subjects at $6 \mathrm{~h}$ and remained at these levels at $8 \mathrm{~h}$ and at $10 \mathrm{~h}$ (CS $0.27 \pm 0.04$ ROUs at $8 \mathrm{~h}, 0.25 \pm 0.03$ ROUs at $10 \mathrm{~h}$; CR $0.49 \pm 0.1$ ROUs at $8 \mathrm{~h}, 0.54 \pm 0.08 \mathrm{ROUs}$ at $10 \mathrm{~h})$. The difference was significant at 6,8 , and $10 \mathrm{~h}$ of PMA incubation $(P<0.05)$. At $6 \mathrm{~h}$, PMA stimulated c-Fos expression on average 1.9-fold and 3.8-fold in the CS and CR subjects, respectively (Fig. 4). Therefore, there was an average twofold greater increase in c-Fos expression in $\mathrm{CR}$ as compared with CS subjects. PMA (10 ng/ml) caused an average 2.2-fold increase $(n=3)$ in c-Fos expression in PBMCs from normal subjects after $6 \mathrm{~h}$, and this increase was similar to that seen in CS individuals.

Effects of preincubation with PMA on GR-GRE binding in $C S$ subjects. DNA binding of the GR was measured by EMSA after $6 \mathrm{~h}$ of incubation in control medium, i.e., in the absence of dexamethasone or PMA, and was given a value of 0 (base- 

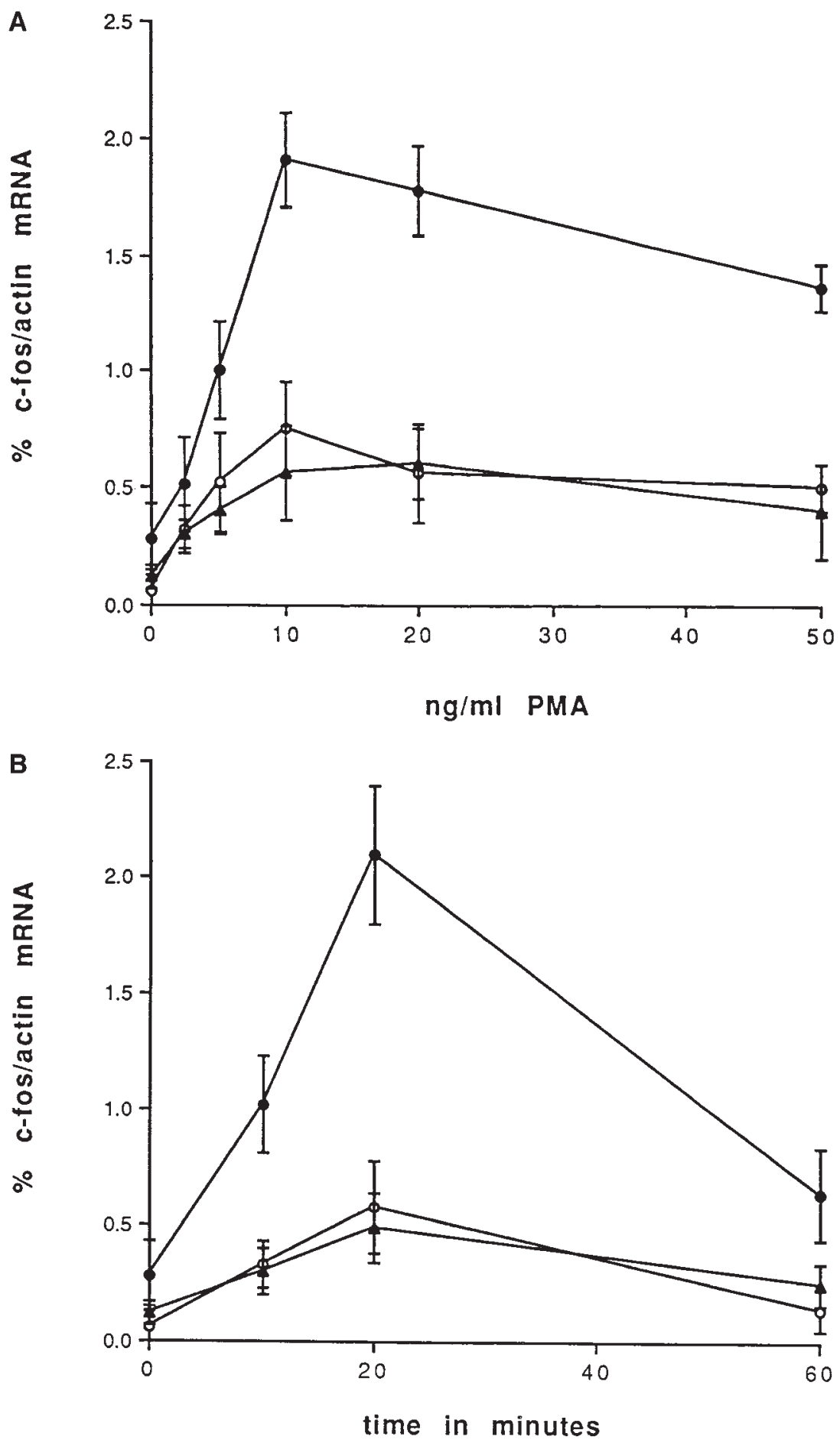

Figure 1. Time and dose dependency of PMAstimulated c-fos activation. PBMCs from CS (open circles, $n=6)$, CR (closed circles, $n=6$ ), asthmatic and nonasthmatic control subjects (closed triangles, $n=6$ ) were incubated in the absence and in the presence of $0-50 \mathrm{ng} / \mathrm{ml}$ PMA $(A)$ at different time points up to $60 \mathrm{~min}(B)$. Results are expressed as percentage of c-fos mRNA transcripts/ $\beta$-actin mRNA transcripts. Each point represents the mean \pm SEM.

line) (Fig. 5, lane 1). When PBMCs from CS subjects $(n=6)$ were incubated for $60 \mathrm{~min}$ with dexamethasone $(1 \mu \mathrm{M})$, there was a marked increase in GR-GRE binding ( $+656 \pm 223 \%$ above baseline) (Fig. 5, lane 2). This was in contrast to the markedly reduced GR-GRE binding seen in the CR group $(+12.5 \pm 5 \%$ increase above baseline, $P<0.01$, data not shown, $n=6)$ which supports previously reported observations (10). Preincubation of PBMCs in PMA $(10 \mathrm{ng} / \mathrm{ml})$ in the absence of dexamethasone for $6 \mathrm{~h}$ or $10 \mathrm{~h}$ caused a reduction in basal GRGRE binding levels to $-20 \pm 4 \%$ and $-28 \pm 6 \%$ from baseline, respectively (Fig. 5, lanes 3 and 4). Preincubation of PBMCs for $6 \mathrm{~h}$ with $10 \mathrm{ng} / \mathrm{ml}$ PMA followed by incubation with $1 \mu \mathrm{M}$ dexamethasone for 60 min resulted in cells from CS individuals failing to show increased GR-GRE binding ( $-5 \pm 4 \%$ compared with control samples) (Fig. 5, lane 5). In these CS subjects, the reduction in GR-GRE binding was associated with an average increase in the c-fos/actin mRNA ratio from 0.09 to $0.7 \%$ and a twofold increase in c-Fos protein $(0.21-0.43$ ROUs) as measured by Western analysis. Therefore, a PMAinducible factor converted a CS to a CR phenotype in vitro. 
CS PMA-

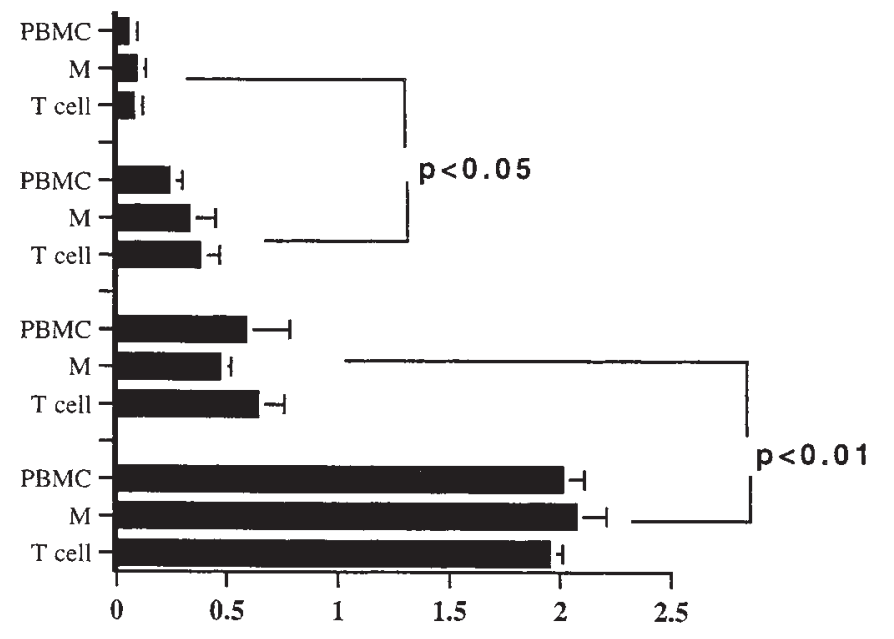

\% c-fos/actin

Figure 2. c-fos mRNA under basal and stimulated conditions in PBMCs, T cells, and monocytes of $\mathrm{CS}$ and CR asthmatic patients. Total PBMCs $(n=$ $12)$, T cells $(n=3)$, and monocytes $(M, n=3)$ derived from $\mathrm{CR}$ and $\mathrm{CS}$ subjects were incubated in the absence $(P M A-)$ or in the presence of $10 \mathrm{ng} /$ ml PMA $(P M A+)$ for 20 min (PBMCs, $n=6$; $\mathrm{T}$ cells, $n=3$; monocytes, $n=3$ ). Data for c-fos are expressed as a percentage of the corresponding $\beta$-actin mRNA transcripts per microgram of original RNA. Each bar represents the mean \pm SEM.

Coimmunoprecipitation of $A P-1$ and $G R$. Immunoprecipitation with anti-human GR antibody followed by Western blot detection with anti-human c-Fos antibody detected the presence of a specific $55 \mathrm{kD}$ c-Fos band in both CS and CR sub- jects. The converse experiment using anti-human c-Fos antibody to precipitate protein followed by Western analysis using anti-human GR antibody demonstrated a specific 94 kD GR band in both CS and CR subjects. Immunoprecipitation with

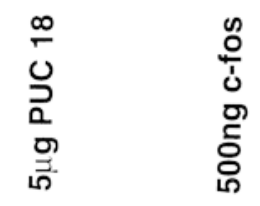

CR-

$\mathrm{CR}+$

\section{CS-}

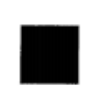

$\mathrm{CS}+$

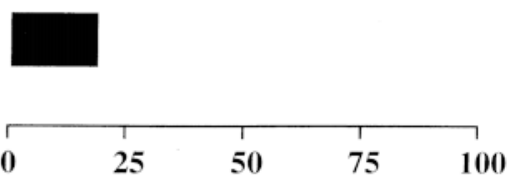

Figure 3. c-fos transcription rate in $\mathrm{CS}$ and $\mathrm{CR}$ asthmatic subjects. PBMCs from CS and CR asthmatic subjects were incubated for $20 \mathrm{~min}$ in the absence $(C R-)$ or presence $(C R+)$ of $10 \mathrm{ng} / \mathrm{ml}$ PMA for $20 \mathrm{~min}$, and the transcription rate was measured by nuclear run-on. PUC18 represents background cDNA binding. Relative optical densities are plotted in the righthand column after subtraction of background binding. Results are

RELATIVE OPTICAL UNITS 

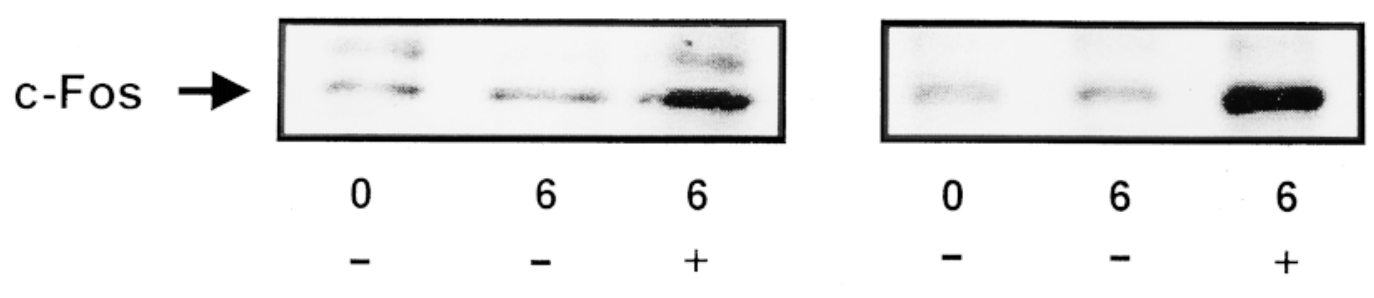

\section{Time (hours) \\ PMA (10 $\mathrm{ng} / \mathrm{ml})$}

B

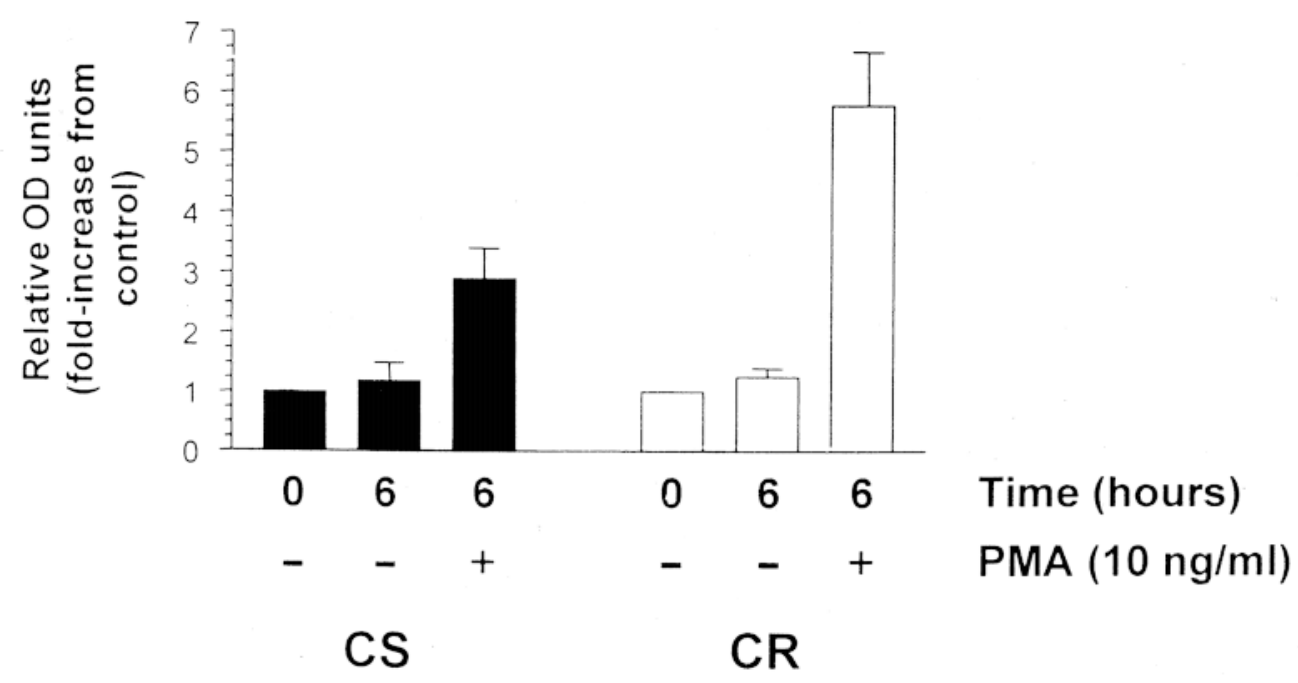

Figure 4. Western blot analysis of c-Fos protein in CS and CR asthmatic subjects. ( $A$ ) Representative Western blot analysis of c-Fos expression following $6 \mathrm{~h}$ of treatment with PMA $(10 \mathrm{ng} / \mathrm{ml})$ or medium control. The lefthand panel shows the result in a CS subject, and the righthand panel shows the result in a CR subject. The absolute baseline expression of c-Fos in these panels cannot be directly compared because they are from separate gels. $(B)$ Graphical representation of the results in $(A)$ and other similar experiments $(n=10)$. The density of the c-Fos band at $t=0$ was assigned a value of 1 , and all subsequent levels are represented as a relative increase from this basal level. Results are presented as the mean \pm SEM.

preimmune serum followed by Western analysis using antihuman c-Fos or GR failed to detect any specific immunoprecipitated bands ( $n=2 \mathrm{CS}$ and 2 CR subjects) (Fig. 6).

Effect of c-fos antisense pretreatment on DNA binding of $G R$ and $A P-1$ in $C R$ subjects. Culture of mononuclear cells from CS subjects with dexamethasone in control medium (1 mM for $60 \mathrm{~min}$ ) increased glucocorticoid receptor DNA binding from $4.2 \pm 1.32$ to $13.76 \pm 2.87$ ROUs. This increase in binding was unaffected by culture with dexamethasone in the presence of either sense $(4.3 \pm 0.7$ to $15.43 \pm 1.71$ ROUs $)$ or antisense (3.9 \pm 1.8 to $14.6 \pm 1.62$ ROUs) c-fos oligonucleotides (Fig. $7 A$ ). Culture of mononuclear cells from $\mathrm{CR}$ asthmatics with dexamethasone (1 $\mathrm{mM}$ for $60 \mathrm{~min}$ ) induced little induction of GRGRE binding in cells preincubated with media $(5.03 \pm 0.64$ to $7.6 \pm 1.66$ ROUs) or with c-fos sense oligonucleotide (4.38 \pm 0.47 to $5.98 \pm 1.72$ relative density units) (Fig. $7 \mathrm{~B}$ ). Pretreatment of the same mononuclear cells with c-fos antisense oligonucleotides, however, enhanced the ability of dexamethasone to induce GR-GRE binding by 2.4 -fold (5.8 \pm 0.91 vs. $13.84 \pm 1.59$ relative density units) in these cells. Therefore, incubation of CR mononuclear cells with c-fos antisense oligonucleotides reconstituted $63 \%$ of the reduced GR-DNA binding when compared with CS mononuclear cells under similar culture conditions.

\section{Discussion}

Corticosteroid resistance in chronic asthma has been studied by selecting patients at two polar extremes on the basis of their clinical response to $40 \mathrm{mg}$ of prednisolone daily for $14 \mathrm{~d}$. The finding that both groups of patients had a similar and marked bronchodilatation following inhaled albuterol indicated that all patients had reversible airway obstruction consistent with a diagnosis of bronchial asthma. We hypothesized that the increase in the DNA binding of AP-1, which we observed in unstimulated PBMCs derived from CR subjects, could be explained on the basis of increased generation of AP-1. Using nuclear run-on, RT-PCR and Western blotting, we have demonstrated a 1.7-, 4.2-, and 2.3-fold greater increase in the c-fos transcription rate, mRNA, and protein accumulation, respectively, in CR compared with CS subjects in the absence of PMA stimulation. Similar rates and levels of c-fos mRNA transcription and of c-Fos protein accumulation to the CS group were detected in the nonasthmatic control population, indicating a real increase in the $\mathrm{CR}$ group rather than a decrease in the CS group.

Nuclear run-on experiments, which allow direct measurement and comparison of specific gene transcription, indicate that the increase in c-fos levels in CR subjects represents an in- 


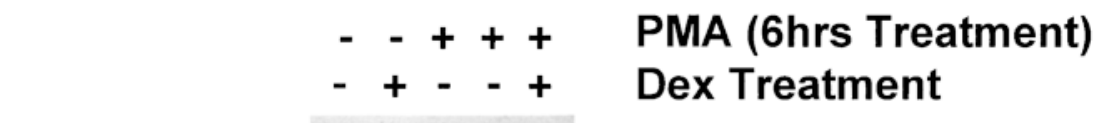

GRE $\rightarrow$

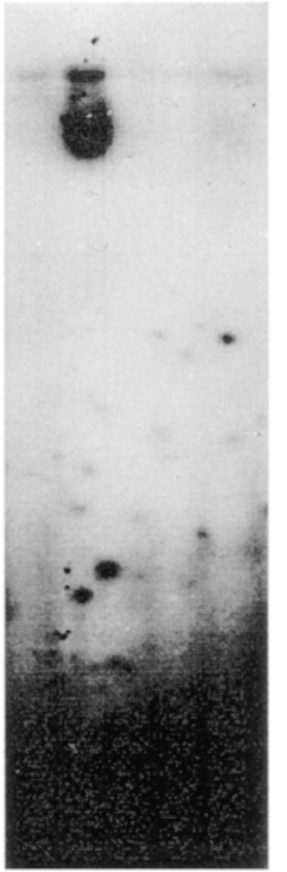

12345

CS

Figure 5. Effects of preincubation with PMA on GR-GRE binding in CS subjects. Representative electrophoretic mobility shift assay on $2 \times 10^{6}$ PBMCs isolated from a CS subject. GRE binding of the GR was measured by EMSA. Lane 1 is GRGRE binding in control medium (dexamethasoneve, PMA-ve) and was given a value of 0 (baseline). Lane 2 is GR-GRE binding after incubation for 60 min with $1 \mu \mathrm{M}$ dexamethasone. Lanes 3 and 4 represent preincubation in $10 \mathrm{ng} / \mathrm{ml}$ PMA in the absence of dexamethasone for $6 \mathrm{~h}$ or $10 \mathrm{~h}$, respectively. Lane 5 is GR-GRE binding after preincubation for $6 \mathrm{~h}$ with $10 \mathrm{ng} / \mathrm{ml}$ PMA followed by incubation with $1 \mu \mathrm{M}$ dexamethasone for $60 \mathrm{~min}$.

crease in its transcription but does not exclude contributions from a decrease in its degradation or transport from the nucleus to the cytoplasm. This is an important observation because c-fos mRNA transcripts are rapidly degraded via a cycloheximide-dependent RNase and an AU-rich sequence in its $3^{\prime}$ untranslated region. These observations support the view that PBMCs from CR asthmatics are overgenerating c-fos or inducible AP-1, which may explain the increase in basal AP-1DNA binding seen in these subjects (12).

When cells were stimulated with PMA, we detected a timeand dose-dependent increase in c-fos mRNA transcription and protein production that was greater in the CR than the CS group. In addition, similar increases in CR asthmatics were detected in both their monocyte and $\mathrm{T}$ cell subpopulations under

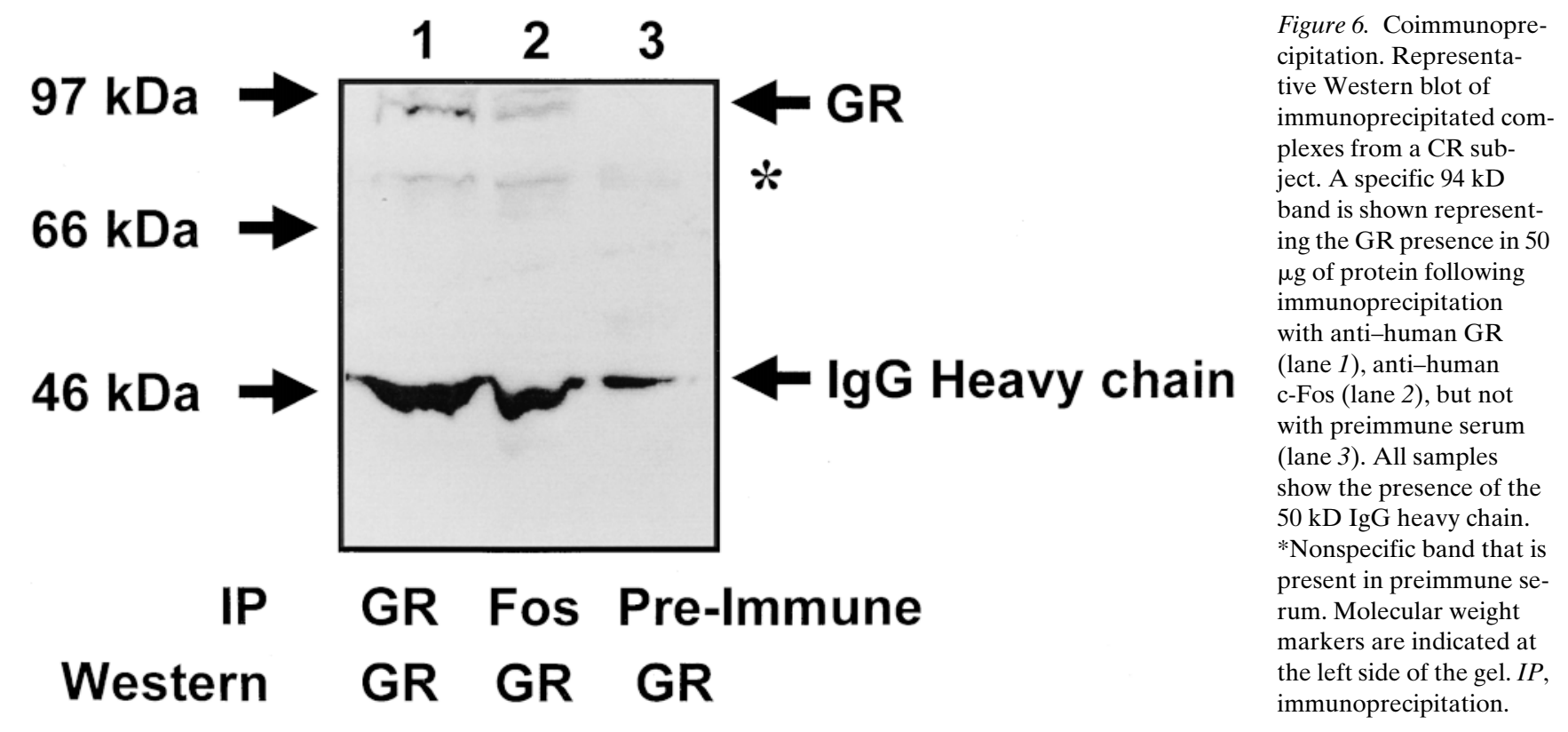




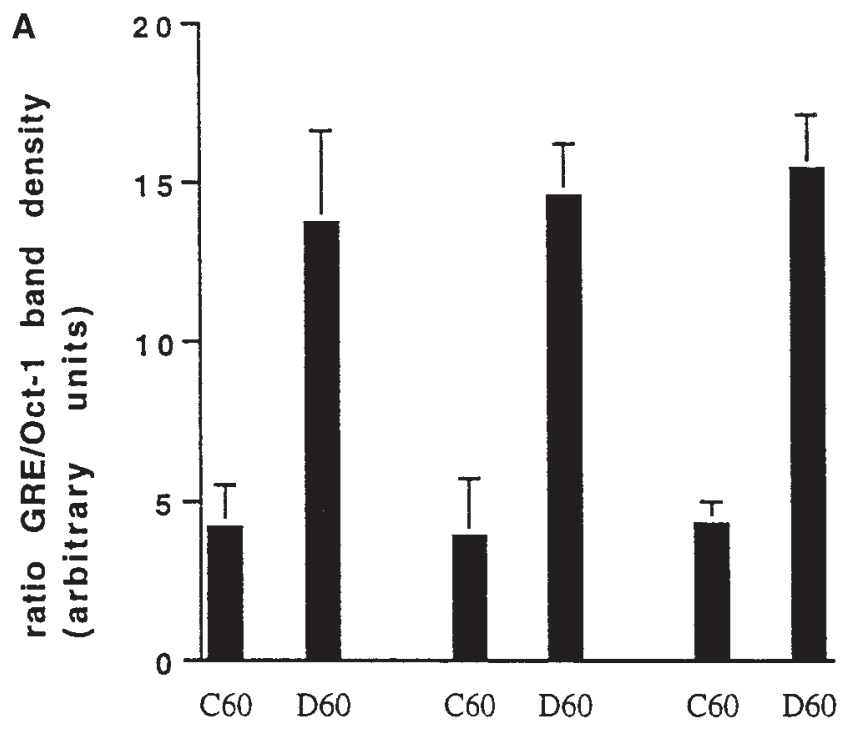

Control Anti-sense Sense

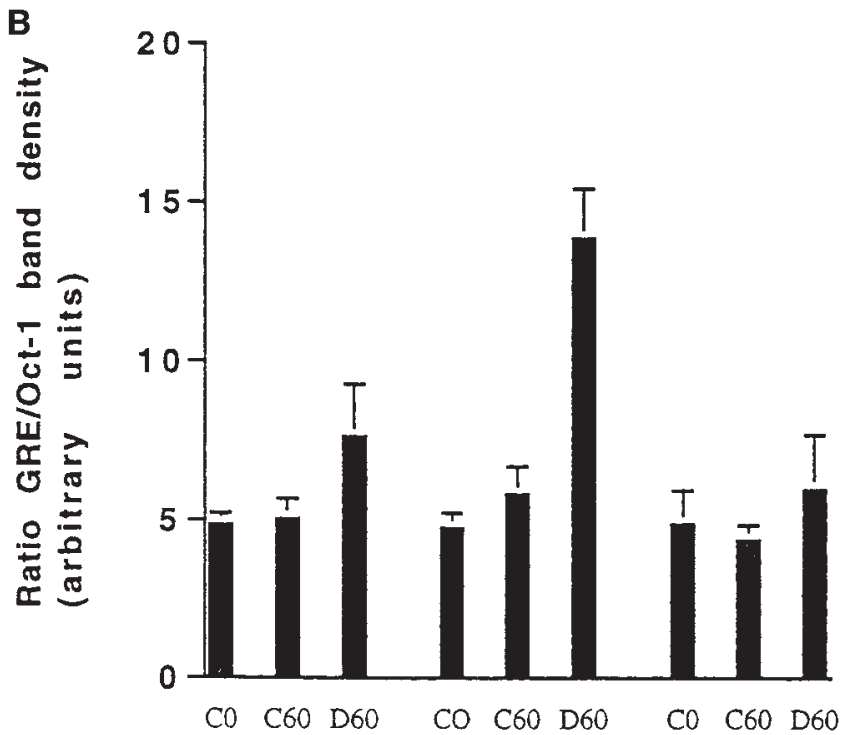

Control Anti-sense Sense

Figure 7. Effect on DNA binding of AP-1 and GR in PBMCs derived from CR subjects with c-fos antisense and sense phophothioate oligonucleotides. Graphical representation of gel shift assays demonstrating the effect of preincubation of mononuclear cells from CS $(A)$ or $\mathrm{CR}(B)$ asthmatics with either control medium, antisense, or sense oligonucleotides on GR-DNA binding followed either before $(C O)$ or after $60 \mathrm{~min}$ of incubation with media alone $(C 60)$ or $1 \mu \mathrm{M}$ dexamethasone $(D 60)$. Data for GR-DNA binding is expressed as a percentage of the corresponding Oct-1-DNA binding. Each bar represents the mean \pm SEM, $n=4$.

basal and stimulated conditions, indicating widespread mononuclear cell activation. This greater upregulation of inducible AP-1 in CR subjects may be specific to c-fos or be associated with a more generalized upregulation of the components of AP-1 or their regulatory pathways and prompts further studies. The results of this study indicate that there is an abnormality in the activation of c-fos transcription in $\mathrm{T}$ lymphocytes and in monocytes derived from CR subjects which may be specific to $\mathrm{c}$-fos or be associated with a more generalized activation of the components of AP-1 or their regulatory pathways which activate through the serum response element (25).

Increased levels of c-fos mRNA and protein have been described in many in vitro and in vivo models of inflammation and proliferation. Rat glomerular mesangial cells demonstrated a 1.6-fold increase in c-fos mRNA at $15 \mathrm{~min}$ and protein at $4 \mathrm{~h}$ as measured by RT-RCR and Western analysis, respectively, after culture in a $30 \mathrm{mM}$ glucose medium in a model of diabetic renal disease (26). Pup cardiac myocytes exposed to acute ischemic stress were found to generate a 5- to 10-fold peak in c-fos mRNA at 15-30 min and protein at 4-12 h (27). In addition, rat hepatocytes demonstrated a dose- and timedependent 8- to 17-fold increase in c-fos expression when exposed to $\mathrm{CCl}_{4}(28)$. In vivo, a vitamin $\mathrm{D}_{3}$ analog induced a protein kinase $\mathrm{C}$-dependent increase in c-fos mRNA associated with epidermal thickening when applied to mouse epidermis for $2 \mathrm{~h}$, which was not present in control epidermis (29). Moreover, livers extracted from rats after treatment with intraperitoneal Freund's adjuvant at different time points demonstrated a 10-fold increase in AP-1-TRE binding after 6-12 h that was associated with a 2.4 -fold increase in $c$-jun, but not c-fos, mRNA and protein levels at 1-3 h (30). These observations indicate that inflammatory or proliferative biological effects are associated with increased generation of c-fos or $c$-jun, depending on the cell type and stimulus involved. Furthermore, the degree of increase in c-fos levels associated with biological effects in these systems suggest that the increases we detected in CR mononuclear cells after PMA stimulation are biologically relevant.

To address the in vitro functional significance of enhanced c-Fos generation, we examined the effects of PMA stimulation on GR-GRE binding. When PBMCs derived from CS subjects were incubated with PMA for $6 \mathrm{~h}$, followed by dexamethasone for $1 \mathrm{~h}, \mathrm{GR}-\mathrm{GRE}$ binding was reduced to levels similar to that seen in CR subjects. In the CS subjects, the reduction in GRGRE binding was associated with an average increase in the c-fos/actin mRNA ratio from $0.09-0.7 \%$ and twofold increase in c-Fos protein (0.21-0.43 ROUs). This finding is consistent, but not proof, that c-Fos played a role in attenuating GRGRE binding. Nevertheless, the possibility that the c-Fos converted a CS to a CR phenotype in vitro by sequestering GR is supported by the demonstration of a direct interaction of the GR with c-Fos protein as demonstrated by coimmunoprecipitation studies (Fig. 6).

To demonstrate a causal relationship between increased basal levels of c-fos and reduced GR-DNA binding, we incubated PBMCs derived from four CR and four CS subjects with dexamethasone and with sense and antisense oligonucleotides to c-fos. Coincubation with dexamethasone and antisense to c-fos increased GR-GRE binding in mononuclear cells from the four CR subjects to $63 \%$ of that seen in the four CS individuals under similar culture conditions (Fig. 7). These findings indicate that increased c-Fos under basal conditions is the predominant inhibitory activity on GR-DNA binding in CR asthma.

The present findings provide a novel mechanism for corticosteroid resistance since an excess of AP-1 would be expected to overcome the antiinflammatory effects of a limited number of available GRs in any cell $(31,32)$. It is not known whether increased c-fos transcription is a primary or secondary defect 
caused by excessive production of a unique pattern of cytokines in asthmatic airways. Previous work has suggested that there is a greater family history of asthma in CR subjects. While this may be consistent with a genetic polymorphism of a component of the c-fos regulatory pathway, resulting in an enhanced response of infiltrating airway mononuclear cells to inflammatory stimuli, there is no direct evidence for this hypothesis. Leung did not show a difference in baseline total white cell counts, percent eosinophils, or activated $\mathrm{T}$ cells in bronchoalveolar lavage samples from $\mathrm{CR}$ as compared with CS subjects. There were increased numbers of bronchoalveolar lavage cells expressing mRNA for IL-2 and IL-4 in the CR group, suggesting a primary defect of cytokine regulation in these patients. The presence of $\mathrm{TH}_{2}$ cytokines has the potential of augmenting AP-1 expression $(14,15)$, which in turn can switch on the production of the same class of cytokines $(16,17)$, leading to a proinflammatory amplification loop. Irrespective of whether enhanced expression of AP-1 is primary or secondary, the net result is an excessive accumulation of this critical transcription factor. These findings support the view that early antiinflammatory treatment in bronchial asthma that suppresses AP-1 should optimize the therapeutic response to subsequent corticosteroid therapy $(33,34)$.

\section{Acknowledgments}

This work is supported by the Medical Research Council U.K.

\section{References}

1. Barnes, P.J. 1995. Drug therapy: inhaled glucocorticoids for asthma. $N$. Engl. J. Med. 332:868-875.

2. Djukanovic, R., J.W. Wilson, K.M. Britten, S.J. Wilson, A.F. Walls, W.R. Roche, P.H. Howarth, and S.T. Holgate. 1992. Effect of an inhaled corticosteroid on airway inflammation and symptoms in asthma. Am. Rev. Respir. Dis. 145:669-674.

3. Lane, S.J., and T.H. Lee. 1997. Mechanisms of corticosteroid resistance in asthmatic patients. Int. Arch. Allergy Immunol. 113:193-195.

4. Lane, S.J., and T.H. Lee. 1996. Corticosteroid resistance in other disease states and tissues. Am. J. Respir. Crit. Care Med. 154:S62-S65.

5. Lane, S.J., and T.H. Lee. 1996. Mononuclear cells in corticosteroid-resistant asthma. Am. J. Respir. Crit. Care Med. 154:S49-S51.

6. Leung, D.Y.M., R.J. Martin, S.J. Szefler, E.R. Sher, S. Ying, A.B. Kay, and Q. Hamid. 1995. Dysregulation of interleukin-4, interleukin-5, and interferon- $\gamma$ gene expression in steroid-resistant asthma. J. Exp. Med. 181:33-40.

7. Sher, E.R., D.Y.M. Leung, W. Surs, J.C. Kam, G. Zieg, A.K. Kamada, and S.J. Szefler. 1994. Steroid-resistant asthma-cellular mechanisms contributing to inadequate response to glucocorticoid therapy. J. Clin. Invest. 93:33-39.

8. Lane, S.J., and T.H. Lee. 1991. Glucocorticoid receptor characteristics in monocytes of patients with corticosteroid-resistant bronchial asthma. Am. Rev. Respir. Dis. 143:1020-1024.

9. Corrigan, C.J., P.H. Brown, N.C. Barnes, S.J. Szefler, J.J. Tsai, A.J. Frew, and A.B. Kay. 1991. Glucocorticoid resistance in chronic asthma-glucocorticoid pharmacokinetics, glucocorticoid receptor characteristics, and inhibition of peripheral-blood T-cell proliferation by glucocorticoids in vitro. Am. Rev. Respir. Dis. 144:1016-1025.

10. Adcock, I.M., S.J. Lane, C.R. Brown, M.J. Peters, T.H. Lee, and P.J. Barnes. 1995. Differences in binding of glucocorticoid receptor to DNA in steroid-resistant asthma. J. Immunol. 154:3500-3505.

11. Lane, S.J., J.P. Arm, D.Z. Staynov, and T.H. Lee. 1994. Chemical mutational analysis of the human glucocorticoid receptor cDNA in glucocorticoidresistant bronchial asthma. Am. J. Respir. Cell Mol. Biol. 11:42-48.

12. Adcock, I.M., S.J. Lane, C.R. Brown, T.H. Lee, and P.J. Barnes. 1995. Abnormal glucocorticoid receptor activator protein-1 interaction in steroidresistant asthma. J. Exp. Med. 182:1951-1958.
13. Angel, P., and M. Karin. 1991. The role of Jun, Fos and the AP-1 complex in cell proliferation and transformation. Biochim. Biophys. Acta. 1072:129157.

14. Mori, A., O. Kaminuma, M. Suko, S. Inoue, T. Ohmura, A. Hoshino, Y. Asakura, K. Miyazawa, T. Yokota, Y. Okumura, K. Ito, and H. Okudaira. 1997. Two distinct pathways of interleukin-5 synthesis in allergen-specific human T-cell clones are suppressed by glucocorticoids. Blood. 89:2891-2900.

15. Wang, C.Y., A.G. Bassuk, L.H. Boise, C.B. Thompson, R. Bravo, and J.M. Leiden. 1994. Activation of the granulocyte-macrophage colony-stimulating factor promoter in T-cells requires cooperative binding of ELF-1 and AP-1 transcription factors. Mol. Cell. Biol. 14:1153-1159.

16. deGroot, R.P., T.B. vanDijk, E. Caldenhoven, P.J. Coffer, J.A.M. Raaijmakers, J.W.J. Lammers, and L. Koenderman. 1997. Activation of 12-O-tetradecanoylphorbol-13-acetate response element- and dyad symmetry elementdependent transcription by interleukin- 5 is mediated by Jun $\mathrm{N}$-terminal kinase stress-activated protein kinase kinases. J. Biol. Chem. 272:2319-2325.

17. Rajotte, D., H.B. Sadowski, A. Haman, K. Gopalbhai, S. Meloche, L. Liu, G. Krystal, and T. Hoang. 1996. Contribution of both STAT and SRF/TCF to c-Fos promoter activation by granulocyte-macrophage colony-stimulating factor. Blood. 88:2906-2916.

18. Saatcioglu, F., F.X. Claret, and M. Karin. 1994. Negative transcriptional regulation by nuclear receptors. Semin. Cancer Biol. 5:347-359.

19. Staynov, D.Z., and T.H. Lee. 1992. Expression of interleukin-5 and granulocyte-macrophage colony-stimulating factor in human peripheral-blood mononuclear cells after activation with phorbol-myristate acetate. Immunology. 75:196-201.

20. Ausubel, F.A., R. Brent, R.E. Kingston, D.D. Moore, J.G. Seidman, J.A. Smith, K. Struhl, editors. 1995. Current Protocols in Molecular Biology. John Wylie \& Sons Inc., Boston.

21. Hanazawa, S., A. Takeshita, S. Amano, T. Semba, T. Nirazuka, H. Katoh, and S. Kitano. 1993. TNF $\alpha$ induces expression of monocyte chemoattractant JE via Fos and Jun genes in clonal osteoblastic MC3T3-E1 cells. J. Biol. Chem. 268:9526-9532.

22. Takeshita, A., Y. Chen, A. Watanabe, S. Kitano, and S. Hanazawa. 1995. TGF- $\beta$ induces expression of monocyte chemoattractant JE/monocyte chemoattractant protein-1 via transcriptional factor AP-1 induced by proteinkinase in osteoblastic cells. J. Immunol. 155:419-426.

23. Rus, H.G., F. Niculescu, and M.L. Shin. 1996. Sublytic complement attack induces cell-cycle oligodendrocytes-S-phase induction is dependent on c-Jun activation. J. Immunol. 156:4892-4900.

24. Yu, K., D. Lu, M.R. Paddy, S.E. Lenk, and M.K. Raizada. 1996. Angiotensin-II regulation of plasminogen-activator inhibitor-1 gene expression in neurons of normotensive and spontaneously hypertensive rat brains. Endocrinology. 137:2503-2513.

25. Treisman, R. 1996. Regulation of transcription by MAP kinase cascades. Curr. Opin. Cell Biol. 8:205-215.

26. Kreisberg, J.I., S.H. Radnik, S.H. Ayo, J. Garoni, and P. Saikumar. 1994. High glucose elevates c-fos and c-jun transcripts and proteins in mesangial cell cultures. Kidney Int. 46:105-112.

27. Webster, K.A., D.J. Discher, and N.H. Bishopric. 1993. Induction and nuclear accumulation of fos and jun proto-oncogenes in hypoxic cardiac myocytes. J. Biol. Chem. 26:16852-16858.

28. Zawaski, K., A. Gruebele, D. Kaplan, S. Reddy, A. Mortensen, and R.F. Novak. 1993. Evidence for enhanced expression of c-fos, c-jun, and the calciumactivated neutral protease in rat liver following carbon tetrachloride administration. Biochem. Biophys. Res. Commun. 197:585-590.

29. Gniadecki, R. 1994. A vitamin D analogue KH 1060 activates the protein kinase $\mathrm{C}-\mathrm{c}$-fos signalling pathway to stimulate epidermal proliferation in murine skin. J. Endocrinol. 143:521-525.

30. Hattori, M., A. Tugores, J.K. Westwick, L. Veloz, H.L. Leffert, M. Karin, and D.A. Brenner. 1993. Activation of activating protein-1 during hepatic acute phase response. Am. J. Physiol. 264:G95-G103.

31. Yang-Yen, H.F., J.C. Chambard, Y.L. Sun, T. Smeal, T.J. Schmidt, J. Drouin, and M. Karin. 1990. Transcriptional interference between c-Jun and the glucocorticoid receptor-Mutual inhibition of DNA binding due to direct protein-protein interaction. Cell. 62:1205-1215.

32. Kerppola, T.K., D. Luk, and T. Curran. 1993. Fos is a preferential target of glucocorticoid receptor inhibition of AP-1 activity in vitro. Mol. Cell Biol. 13: 3782-3791.

33. Haahtela, T., M. Jarvinen, T. Kava, K. Kiviranta, S. Koskinen, K. Lehtonen, K. Nikander, T. Persson, O. Selroos, A. Sovijarvi, et al. 1994. Effects of reducing or discontinuing inhaled budesonide in patients with mild asthma. $N$. Engl. J. Med. 331:700-705.

34. Agertoft, L., and S. Pederson. 1994. Effects of long-term treatment with an inhaled corticosteroid on growth and pulmonary function in asthmatic children. Respir. Med. 88:373-381. 